\title{
Recovering Xiangshan Culture and the Joint Local Development
}

\author{
Ruihui $\operatorname{Han}^{1}$ \\ ${ }^{1}$ Humanities School, Jinan University, Zhuhai, Guangdong Province, China \\ Correspondence: Ruihui Han, Humanities School, Jinan University, Zhuhai, Guangdong Province, China. E-mail: \\ hanruihuihh@hotmail.com
}

Received: April 21, 2014 Accepted: May 5, 2014 Online Published: May 30, 2014

doi:10.5539/ass.v10n11p77 URL: http://dx.doi.org/10.5539/ass.v10n11p77

\begin{abstract}
Xiangshan culture is a beautiful flower in Chinese modern history. The paper analyzes the origin, development, waning and influence of it. It is innovating and pioneering, and has the features of inclusiveness, mercantilism and its own historical heritage. Recovering Xiangshan culture has significant meaning for the local development of economy, society and culture. And that would also provide the positive driving force for the historic progress of all the China.
\end{abstract}

Keywords: Xiangshan culture, Xiangshanese, modernization, social development, cultural development

\section{Introduction}

The requirement of regional integration of Zhongshan, Zhuhai and Jiangmen often appeared in recent years. For example, the bill for combining Zhongshan, Zhuhai and Jiangmen as Zhujiang City was tabled by Guangdong Zhigong Party committee in January, 2014. The same bill was also tabled by the Macau member of CPPCC(Chinese People's Political Consultative Conference) in March, 2013. The city administration partition hinders the regional development of Xiangshan. Integration of the three cities can improve the cooperation with the destruction of administration partition.

The bills are thought as a good idea but cannot be realized easily. The three cities and Macau mainly belong to Xiangshan Region and share the same culture, Xiangshan culture. Recovering and consolidating Xiangshan culture can improve the cultural identification and jiont economic development of the cities.

\section{The Uniqueness of Xiangshan Culture}

"Large difference exists between Xiangshan culture and Chinese traditional culture." (Wang, Y. 2006) The free, equal, open and self-conscious social communication cannot be formed in Chinese traditional agricultural society, as a result of autarkic economy and closed living environment. Marx believed that the small farmers were numerous and with the same living condition caused the lack of diversity of communication. The production mode could not make them contact with each other, but make them isolate with each other...Conservation, law-abiding, retreat and resignation to the vicissitudes of life become normal, and the living condition tended to be a mechanical movement.

That is a different story in Xiangshan region. The huge population mobility and far away from the political center cause the less influence by the traditional Chinese culture and freedom of communication. Generally speaking, Xiangshan region is an immigrant society. People are engaged in different occupations, that makes the region with the diverse characteristics of economic activity, so the custom of it is more open than traditional Chinese culture.

After Macau was administered by Portugal in $17^{\text {th }}$ century, Getting the right place and time, Xiangshan people accepted the western spirit of science and business, education mode, and the rationalism, and innovation of the western world. Xiangshan culture which is combined by the scientific spirit and romantic human spirit is ultimately formed.

\section{Xiangshan Culture Is Valued in the Academic Field}

Some researchers watched closely the important value of Xiangshan culture. For example, Yin Xuzhong's Several Basic Issues about Xiangshan Culture defined Xiangshan culture with special region, and thought Sun Zhongshan was the master of Xiangshan culture and Xiangshan culture was the mode of Lingnan culture. Xiangshan culture was the source of Chinese modernization. Wang jie's On the Characteristic and Essentials of 
Xiangshan Culture believed Xiangshan culture had the characteristic of culture of overseas Chinese and comprador, with the early influence by western culture in China's recent history. The guidance, being inclusive, being realistic and the feeling of unity and brotherhood provided Xiangshan region with huge potential.

The study of Xiangshan culture can improve the integration of Zhongshan, Zhuhai, Jiangmen and Macau culture, deepen the communication and sharing, promote the prosperity of regional economy and culture. The academia has made much research about the Chaoshan culture and Hakka culture, but there is very little research of Xiangshan culture. Xiangshan culture is the important part of Lingnan culture. Understanding Xiangshan culture has great significance for interpretation of Lingnan culture.

The research progress and current status of Xiangshan culture study: Searching the CNKI (Chinese National Knowledge Infrastructure) with the "Xiangshan culture" as the subject term, one would find there are 237 results. The papers about Xiangshan culture were no more than 3 from 1979 to 2005 every year.

In 2006, the articles about Xiangshan culture suddenly amounted to 120 , and $90 \%$ of the articles were published in Zhongshan Daily. Most of the articles emphasized the importance and value of Xiangshan culture.

Some important articles were Cui Guochao's Xiangshan culture: The Spiritual Power of Zhongshan Development, Hubo's The Modern Interpretation of Xiangshan Culture, Xiong Yuezhi's Shanghaiese and Xiangshan Culture, Wangjie's On the Representation and Characteristic of Xiangshan Culture, Yin Xuzhong's Several Basic Issues about Xiangshan Culture, Wang Yuanming's The Value and Meaning of Xiangshan Culture Study, Zhao Liren's Sailing in the Surging Waves, Being Pragmatic and Daring: On the Historical Inheritance of Xiangshan Culture in Contemporary China etc. Such articles established the basis of earlier research of Xiangshan culture.

From 2006, the articles about Xiangshan culture become less soon. There is only one article or so every year during the period from 2006 to 2013 dealing with the topic of Xiangshan culture study. Some important articles such as Ma Zhirong's Xiangshan Cultural Spirit and the Phenomenon of Study abroad in Contemporary China, Zhang Rongfang's Xiangshan Culture and Marine Civilization: the Summary of $6^{\text {th }}$ Marine Culture Symposium, Zhang Yahong's master thesis Pilot Study on Xiangshan County's Town System Geography in Ming and Qing Dynasties, Zhang Wenping's Brief Analysis of Commercial and Comprador Culture, Hu Xiaozhong's PhD thesis The Study on Local Chronicles in Ming and Qing Dynasties, Ye An's On the Origin and Development of Xiangshan Culture and Red Revolutionary Culture.

The papers about Xiangshan culture study published in the academic journals are very few, most of the articles about Xiangshan culture are appeared in the newspaper. There was a time of Xiangshan culture study prosperity, especially in 2006, but it witnessed the decline of it after 2006.

\section{Why should Xiangshan Culture Be Recovered?}

Although the bill of integrating the cities in Xiangshan region is meaningful for the local development, the enforcing of it is not practical in short time, because the administrative region division has existed for more than 30 years, and there are many interest relationships cannot be changed soon. Xiangshan culture, as unique culture which has influenced so many activities throughout the transformation from the old China to modern China, can make the identification for the local people and improve the cooperation of the local economies.

In order to answer the question why Xiangshan culture should be recorded, the paper will investigate the formation, development, features and influence of Xiangshan culture. Through the investigation, we can find that Xiangshan culture is a special regional culture that has its root in the specific time and space. The relationship between immigrants culture and Xiangshan culture will be discussed in the following. Xiangshan culture is distinctive in Guangdong province because of the unique phenomenon of immigrant flow in the end of $19^{\text {th }}$ century and early $20^{\text {th }}$ century, and the Xiangshan region still has the unique geographic condition that has the relationship with the reproduction of the Xiangshan culture despite the administrative regional division. The paper will also discuss the decline of Xiangshan culture, through that we can see that Xiangshan culture is precious for the local development and get some inspiration of how to recover it.

\subsection{The Formation and Development of Xiangshan Culture}

There are four famous places named as Xiangshan in China: Xiangshan in Beijing, Xiangshan in Xiamen of Fujian province, Xiangshan in Xiyao county of Shanxi Province and Xiangshan in Qingzhou of Shandong province. Xiangshan county was an ancient county name which referred to the place from the west bank of Zhujiang to the Lingding bay of south China sea. This region is the place where Xiangshan culture was formed and developed. 
Xiangshan as a name was attributed to the "flower fair tea" in the local Wugui mountain. Such flower was very fragrant, so the local people named the mountain as "Xiangshan" (In Chinese language, Xiang means fragrance ). All the region was named as Xiangshan county since then.

Several thousands years ago, Xiangshan region was composed by some small islands in the sea outside of the Zhujiang River Estuary. Year by year, the area became a natural environment which full of many roads, rivers and hills. Such natural environment provided the local people with fertile soil and beautiful scenery. The daily life of local people was connected with the ocean. Just as the sage of Xiangshan region Zheng Daoshi said:

"Our county is surrounded by the sea in three sides, with the view of roaring waves and the scenery of fertile soil. Our people are sincere and magnanimous, with the character of adventure. There are elegant woods and ravines, with many hills standing closely side by side. The gentlemen living here would enjoy the travelling and seldom have the hardship. The place breeds the noble characters and that last generation by generation. The gentlemen would inherit the family scholarship, or learn by themselves with the interest in the literary pursuits. Although they are different because of richness or poverty, their poems about the frontier fortress are solemn and the poems about the farewell sadness are plangent. Their writing can exceed the ancient master. They live in a remote area and seldom meet with the Zhongyuan people, so they have no the prejudice of master and servant and have the unique way of seeing" (Zheng, 1986).

In the human environment, the formation of Xiangshan culture has a close relationship with the immigrants. Xiangshan region was an important area for the immigrants. The earliest immigrants were relegated officers and later were the refugees and fugitive royal family. Since reform and opening-up, the immigrants are mostly the job-hunting boys and girls. Now almost all the residents in Zhongshan, Zhuhai and Macau where belong to the Xiangshan region are the immigrants.

In Qin and Han Dynasties, Xiangshan region was comprised by some remote small islands. From the Three Kingdoms to the Northern and Southern dynasties, many people fleed from the war areas to Xiangshan. At that time, the region was detrimental to human living, because of the unbearable heat, numerous diseases and vipers. The living environment became better with more people came here and more land being reclaimed. During Sui and Tang dynasties, Xiangshan people became rich. Economic form was based on agriculture and fishery and salt industry coexisted. During Song, Yuan, Ming and Qing Dynasties, numerous refugees fleed to Xiangshan region because of wars. Some craftsmen brought the advanced technologies of central China to Xiangshan, and some official and scholars brought the culture of north China. During the period, the immigrants came from north China play a significant role to promote the economy and culture of Xiangshan region.

Ever since $16^{\text {th }}$ century, the Portuguese administrated Macau. Xiangshan region became the most active area of communication between China and western world. The outlook of the world, view of life and values changed because of the influence of the western world. The advanced science and technology, political ideas, culture and religious outlook, etc after the Renaissance were spread in Xiangshan region. Not only so, lots of Xiangshan people went to exploit the southeast Asia during that time. The Nanyang culture (culture of the countries in tropical oceans of southeast Asia) also appeared in Xiangshan region with the immigrants' trading.

Today's Xiangshan region, which includes Zhongshan, Zhuhai and Macau mainly, accepted a large number of immigrants come from mainland China and overseas. Most of the residents of Zhuhai are immigrants. Macau is one of the three gambling capitals in the world with high degree internationalization. Every year, thousands of job-hunting boys and girls go to Zhongshan, a city with a solid industrial foundation. The immigrants' culture in Xiangshan region is still abundant.

\subsection{Immigrants Play an Important Role in Xiangshan Culture}

The immigrant culture is distinct in Xiangshan region. Such culture was formed during late nineteenth and early twentieth centuries. New wedding, film, gramophone, electric light and telephone were welcomed. Newspaper emerged, taking Immigrants Monthly for example. The houses had the style of both China and the western world. The western industrial and commercial management was introduced, with that the family business rose. Xianshi, Yongan, Xinxin, and Daxin department store were not only popular in Hongkong, but also ranked the toppest in Shanghai. The four big department stores "all had experienced the phase of accumulating the wealth in Australia."' $(\mathrm{Li}, 2012 \mathrm{a})$ The external form of the companies was of western style, but the management of them was family-based. The immigrants changed the regional economy and life a lot, even the men and women judged the potential mates according to whether they had or not the overseas connection.

Between 1942 and 1949, the overseas Chinese investment in China was set up mostly by the Chinese immigrants in southeast Asia and Australia. The sum of the investment of the overseas Chinese in Australia amounted to 
$30.5 \%$ of the investment in Shanghai, and most of the overseas Chinese investors were Xiangshan people. (Lin, 1994) In the 1920s and 1930s, the four department stores, Xianshi, Yongan, Daxin, and Xinxin were all invested in by Xiangshanese who accumulated their wealth in Australia. (Mai, 1989) "By their unique business culture, the four big companies provided a different atmosphere for Shanghai's development, and promoted the prosperity of Shanghai's business culture in modern times." (Li, 2012b)

In recent and contemporary Chinese history, many celebrities have the connection with Xiangshan. There were not only labors, but also the businessmen and intellectuals in Xiangshan region went abroad at that time. The most important one in the intellectuals was Sun Zhongshan, the forerunner of Chinese revolution. Many celebrities changed the course of history. The paper will address this topic in "the influence of Xiangshan culture".

The economic development of Xiangshan has intertwined relationship the overseas. For example, after 1795, the sericulture in Guzhen Town of Xiangshan region came to its climax for the first time, because in 1795, guangzhou became the only one foreign trade port, as a result, the silkworm produced in Guangdong went through the root and the price of it soared. The profit of the sericulture was ten times of the rice. After the reform of China, lighting was of paramount importance in Guzhen Town's industry. Thousands of lighting companies congest in a little town. That is a very rare phenomenon in the world. Everyweek the companies will send the employees to Hongkong market in order to find the new kind of lights. Once the new kind of lighting is sold in Hongkong, the modeled and converted products would appear in Guzhen Town one week later. Xiangshan people absorb the western technology, culture and business mode eagerly.

\subsection{Features of Xiangshan Culture}

From the perspective of human environment, Xiangshan culture is influenced by the immigrant culture. Most of the Xiangshan people are immigrants, so Xiangshan people have broad vision and flexible mind. Compared to the inlanders, Xiangshan people are more pragmatic and have more consciousness of commercial production. The picturesque scenery provides Xiangshan people with sensitivity and romanticism. With detailed analysis, one would find Xiangshan culture has the following features:

First, Xiangshan culture has its own historical heritage. The paramount factor of Xiangshan culture is immigrant culture, which has the clear development vein in history, and the immigrant culture composes the difference between Xiangshan culture and the Central Plain culture. From Qin and Han dynasties to contemporary times, immigrant culture is kept in Xiangshan culture, and such immigrant culture makes Xiangshan people always be the first and constantly strive for progress.

Second, Xiangshan culture has the feature of inclusiveness. In history and contemporary times, the coexistence of plural cultures and peoples never causes the dispute and conflict. "The history of Xiangshan region is the history of accepting the immigrants, and it is also a history of inclusiveness."'(Wang, 2006) That is totally different from hakka culture, in which the Hakkapeople conflicted with the aboriginals for long time. Xiangshan people can always get harmony and coexistence with the immigrants, no matter they come from the Central Plain or the overseas.

Third, Mercantilism is one importance feature of Xiangshan culture. With the geographical advantage of coastal area, Xiangshan region is an important trading port, and it witnesses the prevalence of mercantilism. In 1152, Shiqi of Xiangshan region was the distribution center. In the following Yuan and Ming dynasties, eighteen famous huge stores had been established. In 1685, Macau of Xiangshan region was the only trading port in Guangdong province for the contact between the west and China. (Xia, 1967) Since long time ago, the unique geographical and historical features make Xiangshan people value the commercial development. Zheng Guanying of later Qing dynasty, a Xiangshanese entrepreneur, emphasized the development of business and industry in his Alert in Millennium frequently. He put forward the slogan: "Learing the war is not as worthy as learning business." The earliest comprador class rose up in Xiangshan region, and some immigrants of Xiangshan became the super-rich with their striving in modern Chinese history. Besides, Xiaolan, Shiqi, Qianshan and Xiangzhou of Xiangshan region all became the famous towns because of the thriving business. People live in Xiangshan region are business-oriented.

Fourth, Xiangshan culture is pioneering and innovating. "The strong will to pursuit the innovation is an important feature of Xiangshan culture." ( $\mathrm{Li}, 2006)$ The unique geographical position privileged Xiangshan region as earlier trading port. Xiangshan people prefer to try new things and take risks. With flexible mind, broad vision and pragmatic action, they are ahead of time and play a positive role in the modernization of China. 


\subsection{The Influence of Xiangshan Culture}

Xiangshan culture gave birth to the modernization of China in recent history. "As a special cultural field, Xiangshan culture is not only the epitome of Lingnan culture, but also an important origin of Chinese modernization." (Yin, 2006) The largest trading port of China after 1843 was Shanghai. Numerous Xiangshan people went to Shanghai at that time, and soon became the leading figures in commercial and political circles. Before 1853, there were 80 thousand Guangdongese in Shanghai (Lanning \& Couling, 1921). The proportion of Xiangshanese was the most in Guangdongese. (Xiong, 2006)

The earliest Xiangshan people went to Shanghai were the compradors. At that time, Shanghai replaced Guangzhou as the most important foreign trading center, and that drew lots of Xiangshan people. "Among the modern immigrants in Shanghai, Xiangshanese amounted to 30,000 people at most. The absolute figure was not big and the proportion was not high, but the influence was great. In the fields of economy, politics, society and culture, many Xiangshan people were successful and famous." (Xiong, 2006)

The famous compradors and entrepreneurs in Shanghai, such as Tong King-sing, Tang Tingzhi, Zheng Guanying and Xurun, etc were all Xiangshanese. "In modern history, although the period of Xiangshan commerce's origin, formation and developing seemed very short, but Xiangshan commerce played a very important role in Chinese commerce history, especially in the history of foreign trading and commercial culture." ( $\mathrm{Hu}, 2006)$

The economic foundation determines the superstructure. The culture celebrities in modern China whose ancestral home was Xiangshan were more than 100 . They were active in the realms of education, medicine, politics, economy and military etc. Xiangshan people as No.1 in the realms were more than 30, for example, Sun Zhongshan as the first person in moder China revolutionary, Huangkuan as the first person of western medicine in China, Liang Ruhao as the first foreign minister, Cai Shaoji as the first president of the first university of China, Peiyang University, Zhong Rongguang as the first president of Lingnan University, Su Zhaozheng as the first leader of Chinese labor movement, Make Yingbiao as the first person in Chinese department store, Yung Wing as the first person studied abroad, Rong Guotuan as the first Olympic champion of China...All those xiangshanese pioneered in modernization of China.

"If Pearl River Delta is the major birthplace of Chinese modern culture, as the core of modern Pearl River Delta, Xiangshan culture is the foundation of Chinese modern culture." ( $\mathrm{Li}, 2007)$ Many sources of contemporary thoughts of China can be traced to Xiangshanese, and making the first attempt was one feature of Xiangshanese. Although Xiangshan culture was not the mainstream culture as Central Plain culture, it influenced the whole modernization of China.

\subsection{Decline of Xiangshan Culture}

Xiangshan County existed for 800 years, from 1152 to 1925. In 1925, in order to commemorate Sun Zhongshan, Zhongshan County, one part of Xiangshan County was established. That means Xiangshan county as an administrative region disappeared in China. In 1952, on the advice of Ye Jianying, one part of Zhongshan county was disengaged and established as Yumin county, which was called in 1953 as Zhuhai county. In 1979, Zhuhai county was renamed as Zhuhai city. Zhuhai city became the fourth economic special zone of China in 1980.

In the process of establishment of Zhongshan county and Zhuhai city, Xiangshan county was gradually forgotten. Xiangshan culture also declined compared to Hakka culture, Chaoshan culture and Guangfu culture, which are active in Guangdong province. Xiangshan people's historical contribution is also understated in cultural context.

\subsubsection{Reasons for the Decline of Xiangshan Culture}

The decline of Xiangshan culture is not only the result of administrative region division, but also the result of disappearance of literati class in rural areas and waning influence of Xiangshan people on economy.

First, the administrative region division of Xiangshan. Xiangshan county was be divided to three parts mainly, Zhongshan, Zhuhai and Macau. Until 1998, Macau was handed back to China and became a special administrative zone. Zhuhai became a special economic zone in 1980, and the mainlanders should show their Border Pass to get into Zhuhai until 2006. Border Pass is still needed if the mainlanders go to Macau. The division makes every part of the former Xiangshan region develop its new cultural feature. People cannot find the integrated Xiangshan culture in such cities.

Jared Diamond believes the creation and progress of civilization is in proportion to the scale of human communities and the openness of its geographical position. The lack of communication of the cities is one important factor. They not only lack of the communication with each other, but also have less cultural communication with the western world compared to the situation in recent history. Macau is an international 
gambling city, but it has a strict pass system. The prosperity of communication between western world and China in $19^{\text {th }}$ century cannot be reproduced. However communication with the overseas is necessary to the formation of Xiangshan culture. If the region had not been divided, Xiangshan culture would be remembered more clearly.

Second, the disappearance of literati class in the rural areas. Some features of theXiangshan festivals have disappeared in recent years. Take the Chrysanthemum Festival in Xiaolan town. For example, in 1736, Xiaolan held the first Chrysanthemum Festival in history, then held the festival every 60 years. Every year or every several years Xiaolan town would hold a small Chrysanthemum Festival. In ancient times, the literati would compose poems, paint pictures and drink, which was a romantic scenery. During the festival, there would be the chrysanthemum dramas. The tradition is not well-kept in recent years. Developing economy and attracting investment become the main goal of the local government. Although there would be the correspondent celebration in such festival, the nature has been changed. There is no literati who would compose the poems and paint pictures.

The literati class disappeared in the later Qing dynasty. Private teachers in the rural areas, who could also be called as Shushi in Chinese, were the main part of the literati class. "Three characteristics of transition of Shushi can be categorized for the period from Late-Qing Dynasty to the People' Republic of China: firstly, Shushi as an occupation became less attractive due to the abolishment of Keju competition system, which was the major path for Shushi to be involved in the traditional political society; secondly, the professional behavior of Sishu has been changed due to the establishment and dissemination of modern schools; and thirdly, Shushi as a class became diminished due to the narrower space in the society. The evolution of Shushi class from comfortable existence, survival to disappearance represents its status being challenged and destroyed by the modern education..." (Jiang, C. The Disappearance of a Social Class in China: A Study of Shushi Since Late-Qing Dynasty. East China Normal University PhD Thesis. P6)

There were lots of famous academies in Xiangshan region from Later-Qing dynasty to 1949, but the academies have already been abandoned, even some buildings of the academies were destroyed. The correspondent literati class has disappeared for a long time.

The literati handed down Chinese traditional culture generation by generation. With the disappearance of literati class, some important traditional cultural phenomena also disappeared. The inheritance of Xiangshan culture was disrupted.

Third, the waning of economic and political influence of Xiangshan people. "There were four aspects that had the most lage influence. First, comprador groups started early and had great influence. Second, global department store had four companies that established the fashion and upgraded Shanghai's status as business center and its service image. The third was the Xiaodaohui Uprising. The fourth is the negotiation in the Bund Garden." (Xiong, 2006: 146-155) The communication between China and the western world in most of Xiangshan region tapered off after 1949, especially in the Cultural Revolution. The situation got better after reform and openness in China since 1979. Compared to that in Later-Qing dynasty, Xiangshan people's influence on economy and politics waned. Correspondently, the memory of Xiangshan Culture faded.

\subsubsection{Results of the Decline of Xiangshan Culture}

The decline of Xiangshan Culture has the negative influence on society and economy. That is revealed in the following aspects:

First, the decline of Xiangshan culture is to the disadvantage of the local economic development. Macau is the special administrative zone, whose main income source is gambling and entertainment business. Zhuhai is a tourism city, and Zhongshan is an industrial city. The three cities complement each other in economy. The division of the Xiangshan region and decline of Xiangshan culture cause the lack identification of the three cities. That would weaken the cooperation of the three cities in the economic sphere.

Second, the decline of Xiangshan culture is to the disadvantage of inheritance of local culture. There are many favorable factors in Xiangshan culture for the social development. Xiangshan culture gave birth to the excellent innovative thought in the modernization of China. Developing Xiangshan culture could provide the positive driving force for the social progress. For a long time, lots of Guangdong region was regarded as lack of culture by some people. In fact, Guangdong province never lack of culture, but some parts of its culture are not recognized by the dominant culture and cannot develop smoothly. Valuing and developing Xiangshan culture cannot only prosper Chinese culture, but also enhance the self-confidence of Xiangshan people.

Third, the decline of Xiangshan culture is to the disadvantage of social development of Xiangshan region, for culture provides the potential of social development. 
"Developing the culture is involved in not only the wealth, but also the happiness and safety of the people." (Sun, 2006) In recent years, Chinese government pays attention to the development of cultural industry and tries to make culture as the driving force for the local economy. Zhongshan, Zhuhai and Macau all explore the local cultural characteristics. Taking Zhuhai as an example, Zhuhai government recovered and protected some historical monuments with huge economic input since 2006. The historical monuments included stone inscriptions of calligraphy works of Later-Qing calligrapher Baozhao in Yilanting park.

However, such fragmented protection of historical monuments has not been brought into the narrative of Xiangshan culture, so the significance of it is not obvious. Continuing and developing Xiangshan culture, bringing the historical monuments of Zhongshan, Zhuhai and Macau into the same cultural narrative, would privilege the joint development of the three cities.

\section{Conclusion}

Xiangshan culture is one beautiful flower in modern Chinese history. It provided the innovative thought for modern China social development, and had the unprecedented impact on China in political, economic and social spheres, but in contemporary times, Xiangshan culture declined and faded out in historical memory.

Xiangshan region was divided into three parts administratively. In recent years, some bills were proposed to integrate the parts of the region in order to privilege the local development. However, the integration of the parts would encounter many difficulties. Recovering of Xiangshan culture has great significant meaning for the identification of the parts and development of the former Xiangshan region, and it also has the positive driving force for the economic, social and cultural development of all the China.

\section{References}

Hu, B. (2006). The Modern Interpretation of Xiangshan Culture. Academic Research, (6), 115-121.

Lanning, G., \& Couling, S. (1921). The History of Shanghai. Kelly \& Walsh, Limit, 229.

Li, G. (2006). The meaning and Value of Xiangshan Culture. South Daily. (Theory Edition) July 27. B2.

Li, N. (2012a). Research on Four Big Companies and Business Culture of Shanghai. Master thesis. Huadong University.

Li, N. (2012b). Research on Four Big Companies and Business Culture of Shanghai. Master thesis. Huadong University.

Li, Q. (2007). Xiangshan Culture: The Foundation of Chinese Modern Culture. Guangdong Social Science, (6), 124-129.

Lin, J. (1994). Selected Materials about History of Modern Overseas Chinese Investment in Domestic Industries. Xiamen University Publishing House.

Mai, G. (1989). The Big Department Stores Established by Xiangshanese. Literature and History of Zhongshan, 17, 53-57. Guangdong Province CPPCC Zhongshan Literature and History Editorial Department.

Sun, Z. (2006). Complete Works of Sun Zhongshan. Beijing: The Chinese Publishing House.

Wang, Y. (2006). Analysing the Cluster Economy of Zhongshan in the Perspective of Xiangshan Culture. Hundred Years and Thousand Years, 605-612.

Wang, Y. M. (2006). Narrative and interpretation of a Regional Culture: Introduction to Xiangshan Culture. Yue Hai Feng, (6), 55-59.

Xia, X. (1967). Recording of China and the West. Taibei: Wenhai Publishing House.

Xiong, Y. (2006). Xiangshanese in Shanghai and Xiangshan Culture. Social Science, (9), 146-155.

Yin, Z. (2006). Some Fundamental Problems about Xiangshan Culture. Social Science, (9), 164-169.

Zheng, D. (1986). A Postscript to Xiangshan Poetry. Xiangshan Poetry. Zhongshan Poetry Publishing House. 318-320.

\section{Copyrights}

Copyright for this article is retained by the author(s), with first publication rights granted to the journal.

This is an open-access article distributed under the terms and conditions of the Creative Commons Attribution license (http://creativecommons.org/licenses/by/3.0/). 